\title{
Selected Health Conditions Among Overweight, Obese, and Non-Obese Veterans of the 1991 Gulf War: Results from a Survey Conducted in 2003- 2005
}

\author{
Steven S. Coughlin, Han K. Kang and Clare M. Mahan \\ Environmental Epidemiology Service (135), Office of Public Health and Environmental Hazards, Department of
Veterans Affairs, 810 Vermont Avenue, NW, Washington, DC 20420, USA
}

\begin{abstract}
Background: Several health conditions and concerns have been reported to be increased among Gulf War veterans including post-traumatic stress disorder (PTSD), chronic fatigue syndrome (CFS), CFS-like illness, and unexplained multi-symptom illness (MSI). As the cohort of Gulf War veterans advance in age, they are likely to be at risk of not only certain deployment-related health conditions but also chronic diseases associated with lifestyle factors.
\end{abstract}

Methods: To clarify relationships between PTSD, CFS-like illness, MSI, and obesity, we analyzed data from a crosssectional survey of health information among population-based samples of 15,000 Gulf War veterans and 15,000 veterans who served during the same era. Data had been collected from 9,970 respondents in 2003-2005 via a structured questionnaire or telephone survey.

Results: Based upon body mass index (BMI) estimated from self-reported information about height and weight, the percentages of Gulf War and Gulf Era veterans who were overweight (BMI 25 to $\leq 29.9$ ), were 46.8\% and 48.7\%, respectively. The percentages who were obese (BMI $\geq 30$ ) were $29.6 \%$ and $28.3 \%$, respectively. Without adjustment for Gulf deployment status (Gulf War vs Gulf Era), age, sex, or other factors, PTSD, MSI, CFS-like illness, and other chronic health conditions were more common among obese veterans than those who were normal weight (BMI 18.5 to $\leq 24.9$ ). In multivariate analyses, PTSD was positively associated with obesity after adjustment for age, sex, Gulf deployment status, rank, income, education, and current smoking. In the model for PTSD, the adjusted odds ratio for obesity was 1.5 (95\% CI 1.2-1.8). No associations were observed between BMI categories and CFS-like illness or MSI in multivariate analysis.

Conclusions: Gulf War and Gulf Era veterans who were obese were more likely to have certain chronic health conditions including PTSD. Associations between Gulf status and CFS-like illness and MSI identified in the 2003-2005 follow-up survey were not accounted for by group differences in the prevalence of overweight or obesity.

Keywords: Body mass, chronic fatigue syndrome, obesity, post-traumatic stress disorder, survey, veterans.

An increasing number of studies have identified overweight and obesity as important health concerns among U.S. veterans of various ages [1-5]. Taking into account evidence from studies conducted in the general population, veterans who are overweight or obese are likely to be at increased risk for adult-onset chronic diseases [6-8]. Obesity is likely to be an important health concern among many veterans including men and women who served during the 1991 Gulf War.

Associations may exist between obesity and adverse health conditions related to service in the Gulf War such as post traumatic stress disorder (PTSD), chronic fatigue syndrome (CFS), and unexplained multi-symptom illness (MSI) [9-13]. For example, PTSD has been associated with obesity and metabolic syndrome in selected veteran populations $[13,14]$. However, previous studies have not studied the relationship between obesity and PTSD in

*Address correspondence to this author at the Environmental Epidemiology Service (135), Office of Public Health and Environmental Hazards, Department of Veterans Affairs, 810 Vermont Avenue, NW, Washington, DC 20420, USA; Tel: (202) 266-4656; E-mail: steven.coughlin@va.gov nationally representative populations of veterans, while adjusting for multiple potential confounding factors. The biological pathways that underlie these associations may relate to the hypothalamic-pituitary-adrenal axis and biological responses to chronic anxiety and stress. Studies of CFS in U.S. populations have suggested that CFS is heterogeneous and includes subgroups of patients who are obese $[15,16]$.

We analyzed data from a follow-up health survey among population-based samples of 15,000 Gulf War veterans and 15,000 veterans who served during the same era. Data were collected from 9,970 respondents in 2003-2005 via a structured questionnaire or telephone survey. The objective of this analysis was to examine the frequency of PTSD, CFS-like illness, unexplained MSI, and selected health conditions among Gulf War and Gulf Era veterans who were underweight, normal weight, overweight, or obese.

\section{METHODS}

Study Population. Data for this study were obtained from a follow-up survey to the 1995 National Health Survey of Gulf War Era Veterans and Their Families [17]. The sampling frame consisted of the same panel of 15,000 Gulf 
War veterans and 15,000 Gulf Era veterans selected for the 1995 survey. Gulf War veterans were sampled from 693,826 U.S. troops who were identified by the Department of Defense Manpower Data Center in Monterey, California as being deployed to the Persian Gulf area during the 1991 Gulf War. Gulf Era veterans were sampled from 800,680 persons who represented about one half of all troops who were in the military between September 1990 and May 1991 but did not serve in the Persian Gulf theaters of operations. Each branch of service (Army, Navy, Air Force, and Marine Corps) and unit component (active duty, reserve, and National Guard) were represented in both groups. A stratified random sampling method was applied to ensure that women and those who served in the reserve or National Guard were adequately represented [17]. Approximately $20 \%$ of the sample were women.

Procedures for ascertaining the vital status and updated address of each of the sampled veterans have been reported previously [17, 18]. A total of 393 of the permanent panel of veterans were deceased by the beginning of the data collection period leaving 29,607 veterans eligible to participate in the survey.

Data Collection Methods. A modified Dillman method was used with mailings conducted in 3 waves [19]. A prenotification letter was initially mailed to each potential participant. A 20-page structured health questionnaire was then mailed to each veteran together with an introductory letter, a consent form, and a pre-addressed stamped return envelope. The second wave mailing took place 10 weeks after the first wave mailing. The third wave mailing extended over a 10 -week period. Post card reminders were sent two weeks after each questionnaire mailing (wave one, two, and three). In the second phase of data collection, telephone interviews of 2,000 veterans who had not yet responded were attempted using computer-assisted telephone interviewing software. All data collection was completed by the end of May 2005.

The survey questionnaire included questions about demographic and socioeconomic characteristics (including education and income), cigarette smoking, functional status, activity limitations, health perceptions, height, weight, chronic medical conditions, and PTSD.

The PTSD checklist (PCL) was used to assess symptoms of PTSD. Respondents rate PCL items on a 5-point Likert scale to indicate the degree to which they have had each of 17 PTSD symptoms during the past month [20]. Possible PCL scores range from 17 to 85 . In the present study, respondents with a PCL score of 50 or higher were considered to have PTSD as described by Blanchard et al. [20].

The 1994 Centers for Disease Control and Prevention case definition of CFS illness [9] was modified for use in this study because of the different time frame [18]. Therefore, the term "CFS-like illness" is used here. CFS-like illness consisted of persistent problems in the past 12 months with fatigue lasting > 24 hours after exertion and persistent problems with a least three of seven symptoms (headaches, sore throat, tender lymph nodes, muscle aches or cramps, joint aches or pain, awaken feeling tired or worn out after a full night of sleep, and difficulty concentrating or reasoning or memory loss) and none of the following medical condition exclusions: arthritis, skin cancer, any other cancer, cirrhosis of liver, hepatitis, diabetes, other endocrine disorder, repeated seizures or convulsions or blackouts, neuralgia or neuritis, disease of genital organs, coronary heart disease, stroke or cerebral vascular accident, tachycardia or rapid heart, asthma, emphysema or chronic bronchitis, and repeated bladder infections.

Unexplained multi-symptom illness (MSI) was defined using self-reported information about unexplained physical symptoms and illnesses (fatigue, muscle or joint pain, headaches, memory problems, digestive problems, respiratory problems, and skin problems, etc.) which persisted for 6 months or longer and which was not adequately explained by an established, conventional medical or mental disorder diagnosis. Such unexplained physical symptoms and illnesses, which are often not labeled, are sometimes diagnosed as chronic fatigue syndrome, fibromyalgia, irritable bowel syndrome, or multiple chemical sensitivity.

Variables Used in the Analysis. The variables used in this analysis included age (treated as a continuous variable), gender, race (white, black, Hispanic, other), education ( $<$ high school, high school or equivalent, some college, associate degree, bachelor's degree, or graduate degree, income $(<\$ 20,000, \$ 20,000$ to $\$ 34,999, \$ 35,000$ to $\$ 49,999$, $\$ 50,000$ to $\$ 74,999, \$ 75,000$ to $\$ 99,999$, or $\geq \$ 100,000$ ), unit component (active duty, reserve, National Guard), rank (officer/warrant officer, enlisted), branch of service (Army, Navy, Air Force, Marines), deployment status (Gulf War, Gulf Era), CFS-like illness, MSI, PTSD, current cigarette smoking (yes, no), and BMI (underweight, normal weight, overweight, obese). Body mass index (BMI) was calculated using self-reported information about height and weight [weight $(\mathrm{kg}) /$ height squared $\left.(\mathrm{m})^{2}\right]$. BMI was categorized as underweight $(<18.5)$, normal weight $(18.5$ to $<25.0)$, overweight (25.0 to 29.9$)$, or obese $(\geq 30.0)$ following the International Obesity Task Force classification [21].

Statistical Analysis. The alpha level was set at 0.05 . For the multivariate analyses, logistic regression was performed to examine BMI and other predictors of the health conditions and medical conditions of interest, including PTSD, CFSlike illness, and MSI, while controlling for all other variables included in the model (age, sex, race, branch of service, Gulf deployment status, rank, income, education and current smoking). In addition to age and race, the potential confounders that were adjusted for in the analysis included stratification variables (sex, branch of service, Gulf deployment status), markers of socioeconomic status (rank, income, education), and cigarette smoking. The model for PTSD was re-run while also including CFS-like illness and MSI as covariates. Tests for 2-way interactions between BMI and other variables included in the logistic model for PTSD were performed using the likelihood ratio test. Persons who were underweight $(n=72)$ were excluded from multivariate analysis because the numbers of events were small. SAS statistical package [22] was used in the analysis.

\section{RESULTS}

The mean ages of the Gulf War and Gulf Era veterans who participated in 2005 were 45.5 and 47.6 years, respectively (Table 1). Based upon body mass index (BMI) estimated from self-reported information about height and 
Table 1. Descriptive Characteristics of Gulf War and Gulf Era Veterans who Participated in the 2003-2005 Follow-Up Survey

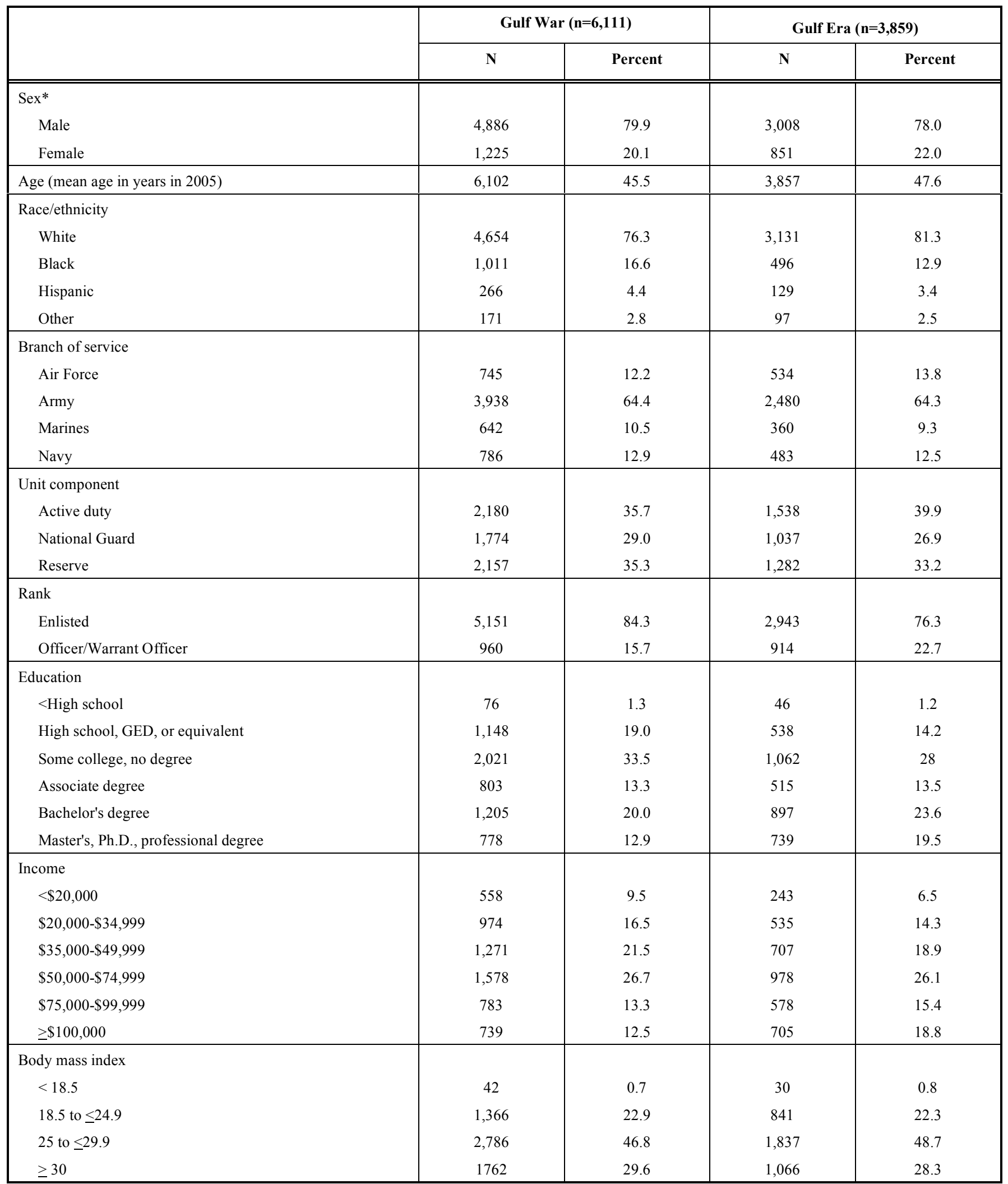

*Quality of gender variable, as reported in DMDC datafile, showed that among $n=9,970$ participants, $n=15$ were miskeyed.

The revised values for "sex" are adopted in Table 1 and in multivariate analyses in this manuscript.

weight, the percentages of Gulf War and Gulf Era veterans who were overweight were $46.8 \%$ and $48.7 \%$, respectively
(Table 1). The percentages who were obese were $29.6 \%$ and $28.3 \%$, respectively. 
Table 2 shows the percentages of Gulf War or Gulf Era veterans who had the health condition of interest by particular BMI categories (underweight, normal weight, overweight, or obese). Without adjustment for Gulf deployment status (Gulf War vs Gulf Era), age, sex, or other factors, PTSD, MSI, CFS-like illness were more common among obese veterans than those who were normal weight (BMI 18.5 to $\leq 24.9$ ). Several other chronic health conditions were also more common among veterans who were obese, including depression, coronary heart disease, arthritis, diabetes, and hypertension (Table 2). Veterans who were obese were also more likely to report a functional impairment or limitation of activities. Self-reported hypertension that had been diagnosed by a doctor was more common among overweight veterans than those who were normal weight (Table 2). About $41.5 \%$ of underweight veterans had been told by a doctor that they had depression and $48.8 \%$ of those who were underweight had unexplained MSI (Table 2).

In multivariate analysis (Table 3), PTSD was positively associated with obesity after adjustment for age, sex, race, branch of service, Gulf deployment status, rank, and current smoking. In the model for PTSD (Table 3 ), the adjusted odds ratio for obesity was 1.5 (95\% CI 1.2-1.8) and a weak association was observed between PTSD and being overweight (adjusted odds ratio $=1.2,95 \%$ CI 1.0-1.5). A comparison of the model with 2-way interaction terms and the nested model with only main effects was significant at the .05 level. Further evaluation of 2-way interaction terms suggested that CFS-like illness modified the effect of Gulf deployment status on PTSD (interaction odds ratio $=0.4$, $95 \%$ CI 0.2-0.8). In addition, there was some indication that BMI modified the effect of CFS-like illness on PTSD (interaction odds ratio $=0.7,95 \%$ CI $0.5-0.9$ ). No other statistically significant 2 -way interactions were observed. No evidence of a problem due to colinearity was found in exploratory analyses based upon crosstabulations and examination of correlations between variables entered into the logistic models. In the models for diabetes and hypertension (results not shown), positive associations were observed with obesity. No associations were observed between BMI categories and CFS-like illness or MSI in multivariate analysis.

\section{DISCUSSION}

About 697,000 U.S. service men and women served in the 1990-1991 Gulf War which liberated Kuwait from Iraqi forces. A number of health studies, including the VA National Health Survey of Gulf War Era Veterans and Their Families and the Longitudinal Health Study of Gulf War Era Veterans, have identified a constellation of symptoms and health conditions associated with Gulf War deployment including PTSD, MSI, and CFS-like illness. Long-term epidemiologic studies have begun to clarify why some but not all Gulf War veterans developed chronic symptoms as a result of deployment and why MSI, CFS-like illness, and

Table 2. Unadjusted Percentages of Self-Reported Health Outcomes and Medical Conditions Among Underweight, Normal Weight, Overweight, and Obese Gulf War and Gulf Era Veterans*

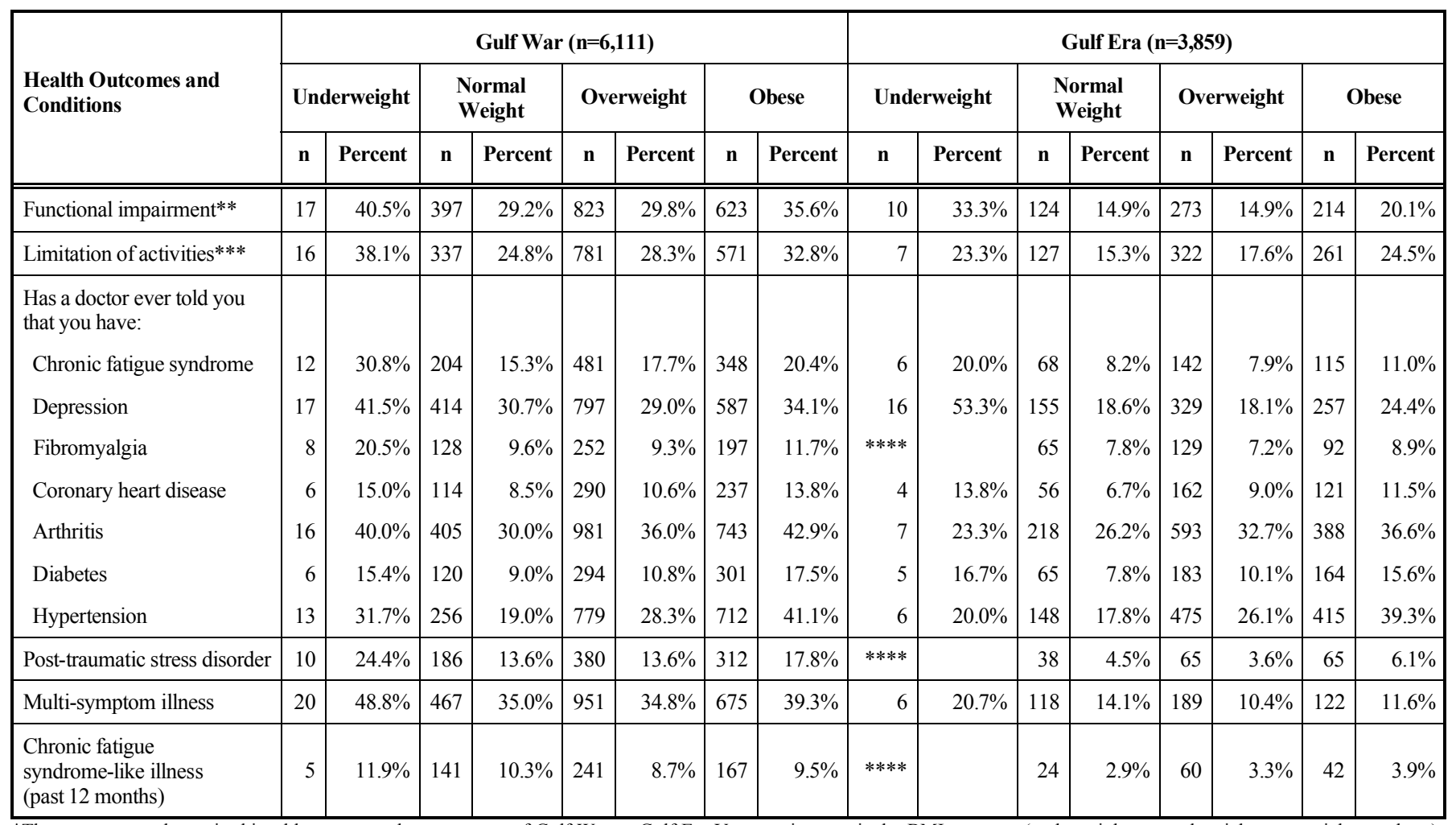

*The percentages shown in this table represent the percentage of Gulf War or Gulf Era Veterans in a particular BMI category (underweight, normal weight, overweight, or obese) who had the health condition of interest. Numbers vary slightly because of missing data.

**Positive response to the question, "Thinking back over the past 2 weeks, did you stay in bed or at home all or part of any day because you did not feel well or as a result of illness or injury?".

***Positive response to the question, "Are you limited in your employment or the kind of work you can do around the house because of any impairment or health problem?". $* * * *$ Numbers too small to report. 
PTSD persist in some subgroups of veterans. Individual variation over time in symptom-based illnesses may be the result of differences in levels of environmental exposures or genetic susceptibility. Although co-morbid conditions may influence the persistence or progression of MSI and CFS-like illness, we did not observe any associations in multivariate analysis between obesity and either MSI or CFS-like illness.

The specific exposures that account for increased risks of MSI and CFS-like illness among Gulf War Veterans are unknown but may include environmental factors such as pyridostigmine bromide or exposure to certain pesticides [23]. Many of the troops were exposed to a wide array of wartime and environmental exposures including psychological stress, solvents, fuels, and pesticides, pyridostigmine bromide pills given to protect troops from effects of nerve agents, smoke from large numbers of oil well fires, and multiple prophylactic vaccines given to protect against anthrax and other infectious agents. Some troops were also potentially exposed to low-level sarin or other nerve agents as a result of the burning of munitions dumps. Multiple exposures often occurred and the effects of two or more combined exposures (for example, mixtures of respiratory irritants such as oil smoke and fuel combustion products and combinations of neurotoxic substances such as certain pesticides and low-level nerve agents) may have potentiated each other [23].

A further issue is that the cohort of Gulf War veterans is advancing in age and these veterans are likely to be at increasing risk of not only certain deployment-related health conditions but also chronic diseases associated with "lifestyle factors" (e.g., physical inactivity and a high caloric or high fat diet). An increasing number of studies have identified overweight and obesity as important health concerns among U.S. veterans of various ages [1-5]. Important associations may exist between obesity and adverse health conditions related to service in the Gulf War such as PTSD [10-13]. Persons with PTSD or depression may be less likely to remain active or to eat a healthy diet. Dietary information was not collected in the current study. Possible biologic pathways for a link between PTSD and obesity may involve the hypothalamic-pituitary-adrenal axis and metabolic changes that occur as a result of chronic anxiety or stress. Taking into account evidence from studies conducted in the general population, veterans who are overweight or obese are likely to be at increased risk for adult-onset chronic diseases such as coronary heart disease, diabetes, hypertension, arthritis, and several forms of cancer [6-8]. Long-term follow up studies of the persistence of PTSD, CFS-like illness, and unexplained MSI, among Gulf War veterans must be conducted in the context of changing risks of chronic diseases that occur among both veteran and non-veteran populations as people get older. Although reverse causation is often an important consideration in studies of comorbid health conditions, all of the men and women included in the current study had to have been physically fit at the time they entered military service. The military has weight limits based upon height, weight, and sex. Each branch of the military has its own body composition standards. Persons with certain health conditions are excluded from military service. Military service itself is often physically demanding. As a result, veteran populations such as those who served in the 1991 Gulf War are not comparable to persons in the general population. The current study provides important new information about comorbidity between obesity or overweight and other important veterans health concerns such as PTSD, CFS-like illness, and unexplained MSI. Although there was some indication that BMI modified the effect of CFS-like illness on PTSD, obesity was an important comorbid health condition among both deployed and nondeployed veterans with CFS-like illness or PTSD.

The troops who served in the 1991 Gulf War were exposed to many stressors including rapid mobilization, wartime hostilities, and concerns about potential chemical attacks. These and other war-time exposures (for example, witnessing deaths or being exposed to hostile fire) may have led to PTSD among some of these veterans). PTSD may lead to other adverse health outcomes and conditions. In previous studies, PTSD has been associated with obesity, metabolic syndrome, and other CHD risk factors in veterans [13-14]. In the current study, PTSD was positively associated with obesity after adjustment for age, sex, Gulf status, and other factors. Although the direction of the association cannot be determined from this cross-sectional analysis of data from the 2003-2005 follow-up survey, it is possible that veterans with PTSD are more likely to consume a high caloric diet or less likely to exercise. This is speculative, however, since the current study lacked data on diet or physical activity.

With respect to other limitations of the current study, exposures such as body mass index and weight were based upon self-reported information. However, studies conducted in non-veteran populations have suggested that the reliability and validity of self-reported information about height and weight obtained in large-scale epidemiologic studies are reasonably good [24]. Estimates of BMI obtained from selfreported information are more accurate among persons less than 55 years of age than those 55 or older and may also vary by gender and ethnicity [25]. A further issue is that estimates of weight may be preferable to BMI for assessing over-weight since weight-for-height indices may not adequately distinguish between adipose individuals and those who are heavily muscled [1]. Response bias is also a possibility in view of the response rate of $34 \%$. In a previous analysis of these data, Kang et al. [18] compared characteristics of respondents and nonrespondents, stratified by Gulf deployment status. In both Gulf War veteran and Gulf Era veteran groups, nonrespondents were more likely to be younger, non-white individuals who served in enlisted ranks at the time of the 1991 Gulf War. In addition, Gulf War veteran participants were more likely women and on National Guard or reserve during the Gulf War service than Gulf War veteran nonparticipants [18].

In conclusion, overweight and obesity are highly prevalent among Gulf War and Gulf Era veterans. These veterans are likely to be at increased risk of chronic diseases associated with overweight and obesity. Consideration of war-related health conditions such as PTSD should take into account not only war time traumatic experiences and other exposures but also the fact that people have a higher risk of chronic conditions (for example, diabetes, cardiovascular disease, and arthritis) as they get older. Gulf War and Gulf 
Table 3. Unadjusted and Adjusted Odds Ratios from Logistic Regression Analysis of Associations Between PTSD and Obesity/Overweight, Demographic and Military Characteristics, and Other Explanatory Variables. Follow-Up Survey of 1991 Gulf War/Gulf Era Veterans conducted in 2003-2005.

\begin{tabular}{|c|c|c|c|c|c|c|}
\hline \multirow[b]{3}{*}{ Covariate } & \multirow{2}{*}{\multicolumn{2}{|c|}{ Crude }} & \multirow{2}{*}{\multicolumn{2}{|c|}{$\frac{\text { Model } 1 \text { for PTSD }}{\text { Adjusted }}$}} & \multirow{2}{*}{\multicolumn{2}{|c|}{$\begin{array}{c}\text { Model } 2 \text { for PTSD } \\
\text { Adjusted }\end{array}$}} \\
\hline & & & & & & \\
\hline & OR & $(95 \% \mathrm{CI})$ & $\mathrm{OR}^{*}$ & $(95 \% \mathrm{CI})$ & $\mathrm{OR}^{* *}$ & $(95 \% \mathrm{CI})$ \\
\hline Age (10 year increase) & 0.9 & $(0.8-0.9)$ & 1.0 & $(0.9-1.1)$ & 0.9 & $(0.9-1.1)$ \\
\hline \multicolumn{7}{|l|}{ Sex } \\
\hline Male & 1.0 & & 1.0 & & 1.0 & \\
\hline Female & 1.1 & $(1.0-1.3)$ & 1.1 & $(0.9-1.3)$ & 0.9 & $(0.8-1.1)$ \\
\hline \multicolumn{7}{|l|}{ Race } \\
\hline Black & 1.0 & & 1.0 & & 1.0 & \\
\hline White & 0.4 & $(0.3-0.5)$ & 0.6 & $(0.5-0.7)$ & 0.6 & $(0.5-0.8)$ \\
\hline Other & 0.7 & $(0.6-1.0)$ & 0.8 & $(0.6-1.1)$ & 0.7 & $(0.5-1.0)$ \\
\hline \multicolumn{7}{|l|}{ Branch of Service } \\
\hline Air force & 1.0 & & 1.0 & & 1.0 & \\
\hline Army & 3.2 & $(2.4-4.2)$ & 2.1 & $(1.5-2.8)$ & 1.7 & $(1.3-2.4)$ \\
\hline Marine & 2.0 & $(1.4-2.9)$ & 1.6 & $(1.1-2.3)$ & 1.4 & $(1.0-2.1)$ \\
\hline Navy & 1.8 & $(1.3-2.5)$ & 1.4 & $(1.0-2.0)$ & 1.6 & $(1.1-2.3)$ \\
\hline \multicolumn{7}{|l|}{ Gulf deployment status } \\
\hline Gulf Era & 1.0 & & 1.0 & & 1.0 & \\
\hline Gulf War & 3.7 & $(3.1-4.4)$ & 3.3 & $(2.7-3.9)$ & 1.9 & $(1.5-2.3)$ \\
\hline \multicolumn{7}{|l|}{ Rank } \\
\hline Enlisted & 1.0 & & 1.0 & & 1.0 & \\
\hline Officer/Warrant & 0.2 & $(0.2-0.3)$ & 0.7 & $(0.5-1.0)$ & 0.8 & $(0.6-1.1)$ \\
\hline \multicolumn{7}{|l|}{ Education } \\
\hline$<$ High school & 1.0 & & 1.0 & & 1.0 & \\
\hline High school, or equivalent & 0.5 & $(0.4-0.9)$ & 0.8 & $(0.5-1.3)$ & 0.7 & $(0.4-1.2)$ \\
\hline Some college, no degree & 0.5 & $(0.3-0.7)$ & 0.8 & $(0.5-1.4)$ & 0.6 & $(0.4-1.2)$ \\
\hline Associate degree & 0.3 & $(0.2-0.5)$ & 0.7 & $(0.4-1.3)$ & 0.6 & $(0.3-1.1)$ \\
\hline Bachelor's degree & 0.2 & $(0.1-0.3)$ & 0.7 & $(0.4-1.2)$ & 0.6 & $(0.3-1.0)$ \\
\hline Master's, Ph.D., professional degree & 0.1 & $(0.1-0.2)$ & 0.7 & $(0.4-1.2)$ & 0.5 & $(0.3-1.0)$ \\
\hline \multicolumn{7}{|l|}{ Income } \\
\hline$<20,000$ & 1.0 & & 1.0 & & 1.0 & \\
\hline$\$ 20,000-\$ 34,999$ & 0.5 & $(0.4-0.7)$ & 0.6 & $(0.5-0.8)$ & 0.7 & $(0.6-0.9)$ \\
\hline$\$ 35,000-\$ 49,999$ & 0.3 & $(0.3-0.4)$ & 0.4 & $(0.3-0.5)$ & 0.5 & $(0.4-0.6)$ \\
\hline$\$ 50,000-\$ 74,999$ & 0.2 & $(0.1-0.2)$ & 0.3 & $(0.2-0.4)$ & 0.3 & $(0.3-0.4)$ \\
\hline$\$ 75,000-\$ 99,999$ & 0.1 & $(0.1-0.2)$ & 0.2 & $(0.1-0.3)$ & 0.3 & $(0.2-0.4)$ \\
\hline$\geq \$ 100,000$ & 0.1 & $(0.0-0.1)$ & 0.1 & $(0.1-0.2)$ & 0.2 & $(0.1-0.3)$ \\
\hline \multicolumn{7}{|l|}{ Current smoking } \\
\hline No & 1.0 & & 1.0 & & 1.0 & \\
\hline Yes & 2.7 & $(2.3-3.1)$ & 2.0 & $(1.7-2.3)$ & 1.9 & $(1.6-2.2)$ \\
\hline \multicolumn{7}{|l|}{ Body mass index $* * *$} \\
\hline 18.5 to $\leq 24.9$ & 1.0 & & 1.0 & & & \\
\hline 25 to $\leq 29.9$ & 0.9 & $(0.8-1.1)$ & 1.1 & $(0.9-1.3)$ & 1.2 & $(1.0-1.5)$ \\
\hline$\geq 30$ & 1.4 & $(1.1-1.6)$ & 1.4 & $(1.2-1.7)$ & 1.5 & $(1.2-1.8)$ \\
\hline \multicolumn{7}{|l|}{ CFS-like illness } \\
\hline No & 1.0 & & & & 1.0 & \\
\hline Yes & 2.2 & $(1.8-2.7)$ & & & 1.2 & $(1.0-1.6)$ \\
\hline \multicolumn{7}{|l|}{ Unexplained MSI } \\
\hline No & 1.0 & & & & 1.0 & \\
\hline Yes & 9.8 & $(8.4-11.3)$ & & & 6.8 & $(5.8-8.1)$ \\
\hline
\end{tabular}


Era veterans who are obese are more likely to have certain chronic health conditions including PTSD. Additional studies are needed of comorbidity between obesity and Gulf War illnesses such as CFS-like illness, unexplained MSI, and PTSD.

\section{REFERENCES}

[1] Almond N, Kahwati L, Kinsinger L, Porterfield D. The prevalence of overweight and obesity among U.S. military veterans. Mil Med 2008; 173: 544-9.

[2] Das SR, Kinsinger LS, Yancy WS Jr, et al. Obesity prevalence among veterans at Veterans Affairs medical facilities. Am J Prev Med 2005; 28: 291-4.

[3] Wang A, Kinsinger LS, Kahwati LC, et al. Obesity and weight control practices in 2000 among veterans using VA facilities. Obes Res 2005; 13: 1405-11.

[4] Kress AM, Hartzel MC, Peterson MR. Burden of disease associated with overweight and obesity among U.S. military retirees and their dependents, aged 38-64, 2003. Prev Med 2005; 41: 63-9.

[5] Nelson KM. The burden of obesity among a national probability sample of veterans. J Gen Intern Med 2006; 21: 915-9.

[6] Yarnell JW, Patterson CC, Thomas HF, Sweetnam PM. Comparison of weight in middle age, weight at 18 years, and weight change between, in predicting subsequent 14 year mortality and coronary events: Caerphilly Prospective Study. J Epidemiol Commun Health 2000; 54: 344-8.

[7] Byun W, Sieverdes JC, Sui X, et al. Effect of positive health factors and all-cause mortality in men. Med Sci Sports Exerc 2010; 42(9): $1632-4$

[8] Calle E. Obesity and cancer. BMJ 2007; 335: 1107-8.

[9] Fukuda K, Straus SE, Hickie I, et al. International Chronic Fatigue Syndrome Study Group: the chronic fatigue syndrome: a comprehensive approach and its definition and study. Ann Intern Med 1994; 121: 953-9.

[10] Atlantis E, Baker M. Obesity effects on depression: systematic review of epidemiological studies. Int J Obes (Lond) 2008; 32: 881-91.

[11] Zhao G, Ford ES, Dhingra S, et al. Depression and anxiety among US adults: associations with body mass index. Int J Obes (Lond) 2009; 33: 257-66.
[12] McFarlane AC. The long-term costs of traumatic stress: intertwined physical and psychological consequences. World Psychiatry 2010; 9: 3-10.

[13] Heppner PS, Crawford EF, Jahi UA, et al. The association of posttraumatic stress disorder and metabolic syndrome: a study of increased health risk in veterans. BMC Medicine 2008; 7: 1.

[14] Cohen BE, Marmar C, Ren L, Seal KH. Association of cardiovascular risk factors with mental health diagnoses in Iraq and Afghanistan War Veterans using VA health care. JAMA 2009; 302: 489-92.

[15] Aslakson E, Vollmer-Conna U, Reeves WC, White PD. Replication of an empirical approach to delineate the heterogeneity of chronic unexplained fatigue. Population Health Metrics 2009; 7: 17

[16] Young HA, Simmens SJ, Kang HK, et al. Factor analysis of fatiguing syndrome in Gulf War Era Veterans: implications for etiology and pathogenesis. J Occup Environ Med 2003; 45: 126873

[17] Kang HK, Mahan CM, Kee KY, et al. Illnesses among United States veterans of the Gulf War: a population-based survey of 30,000 veterans. J Occup Environ Med 2000; 42: 491-501.

[18] Kang HK, Li B, Mahan CM, et al. Health of US veterans of 1991 Gulf War: a follow-up survey in 10 years. J Occup Environ Med 2009; 51: 401-10.

[19] Dillman DA. Mail and Internet Surveys, $2^{\text {nd }}$ ed. Hoboken, NJ: John Wiley \& Sons, Inc 2007.

[20] Blanchard EB, Jones-Alexander J, Buckley TC, Forneris CA. Psychometric properties of the PTSD checklist (PCL). Behav Res Ther 1996; 34: 669-73.

[21] Stevens J, Cai J, Juhaer I, et al. Evaluation of WHO and NHANES II standards for overweight using mortality rates. J Am Diet Assoc 2000; 100: 825-7.

[22] Clark V. SAS/STAT 9.1: User's guide. Cary, NC: SAS Institute Inc 2004.

[23] Committee on Gulf War and Health: Health Effects of Serving in the Gulf War, Update 2009; board on the Health of Selected Populations. Washington, DC: Institute of Medicine 2010.

[24] Gorber SC, Tremblay M, Moher D, Gorber B. A comparison of direct $v s$ self-report measures for assessing height, weight and body mass index: a systematic review. Obes Rev 2007; 8: 307-26.

[25] Stommel M, Schenborn CA. Accuracy and usefulness of BMI measures based on self-reported weight and height: findings from the NHANES and NHIS 2001-2006. BMC Public Health 2009; 9: 421.

This is an open access article licensed under the terms of the Creative Commons Attribution Non-Commercial License (http://creativecommons.org/licenses/by$\mathrm{nc} / 3.0 /$ ) which permits unrestricted, non-commercial use, distribution and reproduction in any medium, provided the work is properly cited. 